\title{
Increased fat cell size: a major phenotype of subcutaneous white adipose tissue in non-obese individuals with type 2 diabetes
}

\author{
Juan R. Acosta ${ }^{1} \cdot$ Iyadh Douagi $^{2}$ • Daniel P. Andersson ${ }^{1} \cdot$ Jesper Bäckdahl $^{1}$. \\ Mikael Rydén ${ }^{1} \cdot$ Peter Arner $^{1} \cdot$ Jurga Laurencikiene $^{1}$
}

Received: 4 June 2015 / Accepted: 26 October 2015 / Published online: 25 November 2015

(C) Springer-Verlag Berlin Heidelberg 2015

\begin{abstract}
Aims/hypothesis We aimed to elucidate the impact of fat cell size and inflammatory status of adipose tissue on the development of type 2 diabetes in non-obese individuals.

Methods We characterised subcutaneous abdominal adipose tissue by examining stromal cell populations by 13 colour flow cytometry, measuring expression of adipogenesis genes in the progenitor cell fraction and determining lipolysis and adipose secretion of inflammatory proteins in 14 non-obese men with type 2 diabetes and 13 healthy controls matched for age, sex, body weight and total fat mass.

Results Individuals with diabetes had larger fat cells than the healthy controls but stromal cell population frequencies, adipose lipolysis and secretion of inflammatory proteins did not differ between the two groups. However, in the entire cohort fat cell size correlated positively with the ratio of M1/M2 macrophages, TNF- $\alpha$ secretion, lipolysis and insulin resistance. Expression of genes encoding regulators of adipogenesis and adipose morphology $(B M P 4, C E B P \alpha$ [also known as $C E B P A], P P A R \gamma$ [also known as $P P A R G$ ] and $E B F 1)$ correlated negatively with fat cell size.

Conclusions/interpretation We show that a major phenotype of white adipose tissue in non-obese individuals with type 2
\end{abstract}

Electronic supplementary material The online version of this article (doi:10.1007/s00125-015-3810-6) contains peer-reviewed but unedited supplementary material, which is available to authorised users.

Jurga Laurencikiene

Jurga.Laurencikiene@ki.se

1 Lipid laboratory, Novum, D4, Department of Medicine Huddinge, Karolinska Institutet, Hälsovägen 7, 14186 Stockholm, Sweden

2 Center of Hematology and Regenerative Medicine, Novum, D4, Department of Medicine Huddinge, Karolinska Institutet, Stockholm, Sweden diabetes is adipocyte hypertrophy, which may be mediated by an impaired adipogenic capacity in progenitor cells. Consequently, this could have an impact on adipose tissue inflammation, release of fatty acids, ectopic fat deposition and insulin sensitivity.

Keywords Adipocyte hypertrophy · Non-obese ·

Subcutaneous adipose $\cdot$ Type 2 diabetes

$\begin{array}{ll}\text { Abbreviations } \\ \text { 7AAD } & \text { 7-Aminoactinomycin D } \\ \text { ATM } & \text { Adipose tissue macrophages } \\ \text { EBF1 } & \text { Early B cell factor 1 } \\ \text { FSC } & \text { Forward scatter } \\ \text { MCP-1 } & \text { Monocyte chemotactic protein 1 } \\ \text { PPAR } \gamma & \text { Peroxisome proliferator-activated receptor } \gamma \\ \text { scWAT } & \text { Subcutaneous WAT } \\ \text { SVF } & \text { Stroma vascular fraction } \\ \text { T-reg } & \text { T regulatory } \\ \text { WAT } & \text { White adipose tissue }\end{array}$

\section{Introduction}

White adipose tissue (WAT) inflammation is an important contributor to the development of obesity-associated type 2 diabetes. Obesity promotes changes in adipose tissue metabolism, such as increased rate of spontaneous (basal) lipid mobilisation (lipolysis) from fat cells, as well as alterations in populations of adipose tissue-residing immune cells. Data in both animal models $[1,2]$ and human obese WAT $[3,4]$ have suggested an increased recruitment and/or differentiation of pro-inflammatory immune cell types (predominantly M1 macrophages) and also, albeit to a less pronounced degree, 
$\mathrm{CD} 8^{+} \mathrm{T}$ cells, B cells, neutrophils, dendritic cells and mast cells $[5,6]$. The overall consequence of these changes is alteration of adipokine and cytokine secretion, which contributes to the development of systemic insulin resistance and type 2 diabetes $[7,8]$. The mechanisms promoting WAT inflammation are not fully understood but it is well-established that a WAT phenotype characterised by large but few fat cells (hypertrophy) associates with a pro-inflammatory adipose state and detrimental metabolic features [9].

Several lines of evidence suggest that differences in adipocyte size could be an important feature or even a predisposing factor for type 2 diabetes. Thus, increased fat cell size is associated with increased risk of developing type 2 diabetes independently of BMI $[10,11]$. Moreover, non-obese individuals with heredity for type 2 diabetes display WAT hypertrophy and insulin resistance [12]. Although type 2 diabetes in lean individuals is most often linked to beta cell dysfunction [13], an important contributing factor could be impaired expansion of WAT resulting in ectopic fat accumulation. This notion is convincingly illustrated by lipodystrophies caused by disturbed function of genes that regulate adipogenesis or lipid storage (e.g. PPAR $\gamma$ [also known as PPARG], PLIN1) [14, 15]. Thus, WAT hypertrophy may cause similar metabolic alterations in both the non-obese and obese state.

While increased adipocyte size correlates with both insulin resistance and impaired adipogenesis in obesity [16], the impact of fat cell size and differentiation as well as the proportion of immune cell populations on the development of type 2 diabetes in non-obese individuals remains elusive. The essential question of whether the changes in WAT that have been observed in obesity are similar to those occurring in non-obese patients with type 2 diabetes is yet unanswered. Therefore, we set out to compare subcutaneous WAT (scWAT) cell populations by flow cytometry, expression of adipogenesis genes in the progenitor cell fraction, scWAT secretion of inflammatory proteins, lipolysis and fat cell size in non-obese men with or without type 2 diabetes.

\section{Methods}

Clinical cohort Twenty-seven non-obese (BMI $<30 \mathrm{~kg} / \mathrm{m}^{2}$ ) men were selected for this study: 14 patients with type 2 diabetes and 13 controls matched for age, sex, body weight and total fat mass. Control individuals were recruited by local advertising. We could obtain data for diabetes duration from 12 patients: seven with short duration (1-3 years) and the remainder with long duration (6-15 years). Age of diabetes onset varied between 38 and 66 years among our patients. This criterion implies that it is highly unlikely that any of the patients had MODY as this form of diabetes usually debuts before 25 years of age.

The participants came to the laboratory after an overnight fast and were instructed not to take their glucose-lowering drugs (insulin treatment was an exclusion criterion) in the morning on the day of examination. Height, weight, waist and hip circumferences and body fat (Tanita TBF-305, Tanita, Arlington Heights, IL, USA) were measured. Venous blood samples were collected for analysis of insulin, glucose and $\mathrm{HbA}_{1 \mathrm{c}}$. $\mathrm{HbA}_{1 \mathrm{c}}$ values were missing for two control individuals. In vivo insulin resistance was assessed by HOMA-IR with the following formula: HOMA-IR=[fasting insulin $(\mathrm{pmol} / \mathrm{l}) \times$ fasting glucose $(\mathrm{mmol} / \mathrm{l})] / 135$ [17]. An abdominal scWAT biopsy was taken as previously described [18]. In a subset of seven diabetic patients and ten controls, a hyperinsulinaemic-euglycaemic clamp procedure was performed as described previously [19] (see also electronic supplementary material [ESM] Methods and ESM Fig. 1).

Characterisation of adipose tissue The adipose tissue was washed in physiological saline $(154 \mathrm{mmol} / \mathrm{l} \mathrm{NaCl})$ and 200 $300 \mathrm{mg}$ of tissue was immediately frozen for later analysis of gene expression. The rest of the WAT was cut into small pieces $(\sim 10 \mathrm{mg})$ and $300 \mathrm{mg}$ was incubated in media for protein secretion and determination of lipolysis (see ESM Methods) and $\sim 1 \mathrm{~g}$ was subjected to collagenase isolation and mean fat cell weight and volume were determined as described previously [20] and discussed elsewhere [21] (see also ESM Methods). Since $>95 \%$ of adipose lipids are triacylglycerols, the density of triolein $(0.915)$ was used for the calculation of lipid weight [22]. Measurement of glycerol release as an index of lipolysis is described in ESM Methods. Determination of secretion and fat cell size could not be performed for one control patient due to a very small biopsy size.

Flow cytometry The stroma vascular fraction (SVF) was isolated after collagenase digestion of scWAT as described [23], and was suspended in FCS supplemented with 10\% DMSO and stored in liquid nitrogen. Upon analysis, the SVF of scWAT from the 27 participants was thawed, washed with PBS- $0.5 \%$ BSA-2 mmol/1 EDTA buffer (BSA A4503; Sigma-Aldrich, St Louis, MO, USA) and passed through a $70 \mu \mathrm{m}$ cell mesh (BD Biosciences, San Diego, CA, USA). Subsequently, the SVF was stained for $30 \mathrm{~min}$ at $4^{\circ} \mathrm{C}$ with fluorophore-conjugated antibodies (listed in ESM Methods) in $50 \mu \mathrm{l}$ BD Horizon Brilliant Stain Buffer (BD Biosciences). After staining, cells were washed, filtered again and resuspended in PBS- $0.1 \%$ BSA-2 mmol/l EDTA buffer. Viability of the cells was assessed using 7-aminoactinomycin D (7AAD) dye (BD Biosciences), which was added to the samples $15 \mathrm{~min}$ before the sorting procedure and constituted a 13th colour in the FACS sorting. Freezing did not affect the viability or frequency of SVF cell fractions (ESM Fig. 2). Cells were sorted using a FACSAria III equipped with $488 \mathrm{~nm}, 633 \mathrm{~nm}, 405 \mathrm{~nm}$ and $561 \mathrm{~nm}$ lasers and the Diva software (BD Biosciences). The purity of the sorted population was confirmed to be typically $>95 \%$ by post-sort analysis. 
The viability of the cells was typically $75 \%-85 \%$. The viability of the SVF cells was very low in one patient $(25 \%)$ and thus cytometry data obtained in this sample was excluded from analysis. Data analysis was performed with FlowJo version 10.0.7.2 software (Tree Star, Ashland, OR, USA).

Gene expression analysis Total RNA from FACS-sorted cell fractions was extracted with the RNeasy Micro Kit (Qiagen, Hilden, Germany) and RNA from scWAT was extracted with RNeasy Lipid tissue (Qiagen) in accordance with the manufacturer's recommendations. RNA concentration was measured using a NanoDrop 2000 spectrophotometer (Thermo Fisher Scientific, Lafayette, LA, USA). The reverse transcription and quantitative PCR (RT-qPCR) analysis is described in ESM Methods. Some samples were excluded from gene expression analysis if duplicate samples (technical duplicates from the same cDNA) showed higher than 0.5 threshold $C_{t}$ differences.

ELISA Cytokine secretion was measured in samples of buffer removed from incubated scWAT pieces $(100 \mathrm{mg}$ of tissue $/ 1 \mathrm{ml}$ of medium) (see above section 'Characterisation of adipose tissue' and ESM Methods). For TNF- $\alpha$ protein secretion, the QuantiGlo ELISA (R\&D Systems, Minneapolis, MN, USA) based on chemiluminescence quantification was employed according to the manufacturer's instructions. For IL-6 and monocyte chemotactic protein 1 (MCP-1) detection the Quantikine ELISA Human IL-6 Immunoassay (R\&D Systems) and Quantikine ELISA Human CCL2/MCP-1 Immunoassay (R\&D Systems) was used, respectively. The secretion of proteins was normalised per $1 \mathrm{~g}$ of lipid in the incubated tissue as described above.

Statistical analysis Prior to study recruitment, a power calculation was made based on differences in fat cell volume. We used data obtained from non-obese men taking part in a previous study of a very large study population [24]. The mean value and standard deviation for this subgroup was used. We had $84 \%$ power to detect a $20 \%$ difference in fat cell volume between 13 controls and 13 diabetic individuals at a $p$ value of $<0.05$. As we included 27 individuals, power increased to $85 \%$. These results suggested that we had a sufficient power to detect even small differences in fat cell size between the groups. IBM SPSS Statistics 22 software was used for statistical analysis (SPSS, Chicago, IL, USA). Data were assessed by Student's $t$ test, Pearson correlation analysis and ANCOVA. Where indicated, values were $\log _{10}$ transformed to achieve normality of distribution. Spearman correlation analysis was applied when values were not normally distributed. A $p$ value $<0.05$ was considered to be statistically significant in all analyses. Data in the tables are presented as mean $\pm \mathrm{SD}$

\section{Results}

Non-obese patients with type 2 diabetes have larger fat cells than healthy controls as a major adipose phenotype The diabetes and control groups were matched for age and anthropometric measures. As expected, the two groups differed in $M$ values, HOMA-IR and plasma glucose levels (Table 1). Adipose tissue lipolysis (glycerol release) and secretion of IL-6 and MCP-1 exhibited no difference between diabetic individuals and controls. Interestingly, adipocyte cell volume was markedly larger in diabetic individuals than in controls (Table 1). In the entire cohort, fat cell volume correlated positively and significantly with HOMA-IR (Fig. 1a), glycerol release (Fig. 1b) and TNF- $\alpha$ secretion (Fig. 1c). Further, glycerol release correlated positively with HOMA-IR (Fig. 1d). TNF- $\alpha$ secretion correlated positively with HOMA-IR (Fig. 1e) and glycerol release (Fig. 1f). Wholebody insulin sensitivity, $M$ value (expressed as mmol infused glucose $/ \mathrm{kg}$ body weight/minute needed to maintain euglycaemia during a hyperisulinaemic clamp) correlated negatively with fat cell volume $(r=-0.62, p=0.007)$ and with TNF- $\alpha(r=-0.586, p=0.017)$ (data not shown). The mentioned correlations were not influenced by type 2 diabetes status as judged by ANCOVA (Fig. 1).

Cell population frequencies do not differ in SVF of nonobese healthy and type 2 diabetes patients We developed a 13 colour flow cytometry antibody panel to quantify major cell populations present in the SVF of scWAT. First, live single cells within the SVF fraction were identified using a combination of 7AAD as a dead cell marker and forward scatter (FSC) gating for doublet exclusion. Haematopoietic cells were identified using CD45 marker, where the monocyte/ macrophage population was defined as CD14-positive cells. M1 and M2 adipose tissue-resident macrophages (ATMs) were subsequently defined as $\mathrm{CD} 45^{+} \mathrm{CD} 14^{+} \mathrm{CD} 3^{-} \mathrm{CD} 206^{+}$ [25] and $\mathrm{CD}_{11 \mathrm{c}^{+}}$or CD11 ${ }^{-}$, respectively [4]. The CD3positive $\mathrm{T}$ cells were further divided into $\mathrm{CD} 4^{+} \mathrm{T}$ helper cells and $\mathrm{CD}^{+} \mathrm{T}$ cytotoxic cells. Within the $\mathrm{CD} 4^{+} \mathrm{T}$ cell population $\mathrm{T}$ regulatory (T-reg) cells were defined and quantified as $\mathrm{CD} 45^{+} \mathrm{CD} 14^{-} \mathrm{CD} 3{ }^{+} \mathrm{CD} 4{ }^{+} \mathrm{CD} 127^{-} \mathrm{CD} 25^{+}$cells [26]. Additionally, the frequency of B lymphocytes $\left(\mathrm{CD} 45^{+} \mathrm{CD}_{14}^{-} \mathrm{CD}^{-} \mathrm{CD}^{+} 9^{+}\right)$was determined. Endothelial cells were defined as $\mathrm{CD} 45^{-} \mathrm{CD} 31^{+} \mathrm{CD} 34^{+}$while adipose progenitor cells were identified as $\mathrm{CD} 45^{-} \mathrm{CD} 31^{-} \mathrm{CD} 34^{+}$. The latter population was collected for further analysis (Fig. 2). When cell frequencies of the above-described populations were analysed in each individual and normalised to the total number of viable cells in each sample, no significant differences were observed between diabetes and control patients (Table 2). Although the average of M1 ATMs was twice as high and the $\mathrm{T}$ cell-to-B cell ratio approximately 1.5 -fold higher in diabetic patients compared with controls, the 
Table 1 Characteristics of non-obese patients with type 2 diabetes and healthy controls

\begin{tabular}{|c|c|c|c|}
\hline Variable & Healthy controls & Type 2 diabetes patients & $p$ value \\
\hline$n$ & 13 & 14 & - \\
\hline Age, years & $57 \pm 11.2$ & $60.5 \pm 9.1$ & 0.37 \\
\hline BMI, $\mathrm{kg} / \mathrm{m}^{2}$ & $25.9 \pm 1.4$ & $26.6 \pm 1.6$ & 0.27 \\
\hline Total body fat, $\%$ & $21.7 \pm 5.0$ & $23.5 \pm 3.6$ & 0.30 \\
\hline Waist circumference, $\mathrm{cm}$ & $92.7 \pm 6.0$ & $96.8 \pm 6.1$ & 0.09 \\
\hline Hip circumference, $\mathrm{cm}$ & $98.1 \pm 2.5$ & $100.2 \pm 3.9$ & 0.11 \\
\hline Waist-to-hip ratio & $0.9 \pm 0.0$ & $1.0 \pm 0.0$ & 0.20 \\
\hline Plasma glucose, mmol/1 & $5.2 \pm 0.5$ & $7.1 \pm 1.3$ & $<0.001$ \\
\hline Plasma insulin, pmol/1 & $43.2 \pm 22.3$ & $54.2 \pm 29.3$ & 0.29 \\
\hline $\mathrm{HbA}_{1 \mathrm{c}}, \mathrm{mmol} / \mathrm{mol}$ & $35.8 \pm 3.4^{\mathrm{a}}$ & $49.4 \pm 8.7^{\mathrm{b}}$ & $<0.001$ \\
\hline $\mathrm{HbA}_{1 \mathrm{c}}, \% \mathrm{NGSP}$ & $5.4 \pm 0.3^{\mathrm{a}}$ & $6.7 \pm 0.8^{\mathrm{b}}$ & $<0.001$ \\
\hline Adipocyte volume, pl & $451.0 \pm 109.5$ & $586.6 \pm 117.0$ & $<0.01$ \\
\hline $\log _{10}$ HOMA-IR & $0.174 \pm 0.016^{\mathrm{c}}$ & $0.395 \pm 0.191$ & 0.01 \\
\hline$M$ value, $\mathrm{mmol} \mathrm{kg}^{-1} \min ^{-1}$ & $0.034 \pm 0.012^{\mathrm{d}}$ & $0.020 \pm 0.012^{\mathrm{e}}$ & 0.03 \\
\hline $\mathrm{TNF}-\alpha, \operatorname{pg}(2 \mathrm{~h})^{-1}(\mathrm{~g} \text { lipid })^{-1}$ & $1,893.4 \pm 1,246.8^{\mathrm{c}}$ & $3,016.2 \pm 1,681.6$ & 0.07 \\
\hline IL-6, ng $(2 \mathrm{~h})^{-1}(\mathrm{~g} \text { lipid })^{-1}$ & $17.4 \pm 18.1^{\mathrm{c}}$ & $15.5 \pm 8.6$ & 0.72 \\
\hline MCP-1, ng $(2 \mathrm{~h})^{-1}(\mathrm{~g} \text { lipid })^{-1}$ & $7.7 \pm 5.9^{\mathrm{c}}$ & $8.0 \pm 3.8$ & 0.84 \\
\hline Adipose lipolysis, $\mu$ mol glycerol $(2 \mathrm{~h})^{-1}\left(10^{7} \text { cells }\right)^{-1}$ & $0.7 \pm 0.2^{\mathrm{c}}$ & $0.6 \pm 0.4$ & 0.62 \\
\hline
\end{tabular}

Data are mean \pm SD

${ }^{\text {a }}$ Clinical variables were measured in 11 patients

${ }^{\mathrm{b}}$ Clinical variables were measured in 13 patients

${ }^{\mathrm{c}}$ Clinical variables were measured in 12 patients

${ }^{\mathrm{d}}$ Clinical variables were measured in 10 patients

${ }^{\mathrm{e}}$ Clinical variables were measured in 7 patients

difference was not significant due to large inter-individual variations and possibly too small a sample size. However, this extensive characterisation of adipose tissue is not feasible in larger groups of patients.

Effect of type 2 diabetes duration on fat cell size and SVF composition We compared all clinical variables, fat cell size, lipolysis and adipose protein secretion in diabetic patients with short-term (1-3 years) or long-term (6-15 years) disease duration and observed that fat cell size was significantly larger in patients with both short-term and long-term diabetes duration (Table 3) than in healthy controls. Furthermore, there were elevations in SVF populations of M1 ATMs and total ATMs in patients with type 2 diabetes of short duration. Interestingly, no significant change in SVF cell populations was identified in patients with long-term type 2 diabetes compared with healthy controls.

Secretion of TNF- $\alpha$ and M1/M2 macrophage ratio correlate positively with fat cell size in non-obese individuals with or without type 2 diabetes We further analysed the association of cell population frequencies with adipose tissue metabolic features and fat cell size. Population frequencies were not normally distributed according to the Shapiro-Wilk test and therefore a Spearman correlation analysis was applied. The results showed a positive association between the M1/M2 macrophage ratio and adipocyte cell size (Fig. 3a). Furthermore, the M1/M2 macrophage ratio correlated positively with $\mathrm{TNF}-\alpha$ secretion as well as glycerol release from scWAT tissue pieces incubated in vitro (Fig. 3b, c). In addition, while the frequency of M1 macrophages correlated positively with TNF- $\alpha$ secretion (Fig. 3d), the M2 macrophage frequency showed no significant correlation with any of the clinical variables (data not shown). Interestingly, the frequency of T-reg cells correlated positively with TNF- $\alpha$ secretion $(\rho=0.46$, $p=0.020)$ and with glycerol release $(\rho=0.51$, $p=0.007$ ) (data not shown). None of the other cell populations displayed any correlations with metabolic variables or adipocyte cell size.

Gene expression analysis indicates an impairment of adipogenesis in non-obese diabetic or non-diabetic individuals with enlarged fat cells As fat cell size constituted the major difference between non-obese type 2 diabetes patients and healthy controls, we investigated whether there were qualitative differences in adipose tissue progenitor populations 
Fig. 1 An inter-relationship between fat cell volume, insulin sensitivity, lipolysis and TNF- $\alpha$ secretion. Associations between fat cell volume and HOMA-IR $(r=0.67, p=0.0002 ; F=0.43$, $p=0.52)(\mathbf{a})$, glycerol release ( $r=0.65, p=0.0004 ; F=2.8$, $p=0.11)(\mathbf{b})$ and TNF- $\alpha$ secretion $(r=0.48, p=0.016 ; F=1.4$, $p=0.25)(\mathbf{c})$ in the subcutaneous fat depot as well as between glycerol release and HOMA-IR ( $r=0.62, p=0.001 ; F=0.29$, $p=0.6)(\mathbf{d}), \mathrm{TNF}-\alpha$ secretion and HOMA-IR $(r=0.57, p=0.003$; $F=0.29, p=0.6)(\mathbf{e})$ and TNF- $\alpha$ and glycerol release $(r=0.78$, $p<0.0001 ; F=0.14, p=0.71)$ (f) were determined in an entire cohort of 27 individuals using Pearson correlation analysis. $F$ values represent an ANCOVA of the influence of type 2 diabetes diagnosis. White circles, healthy controls; black circles, individuals with type 2 diabetes
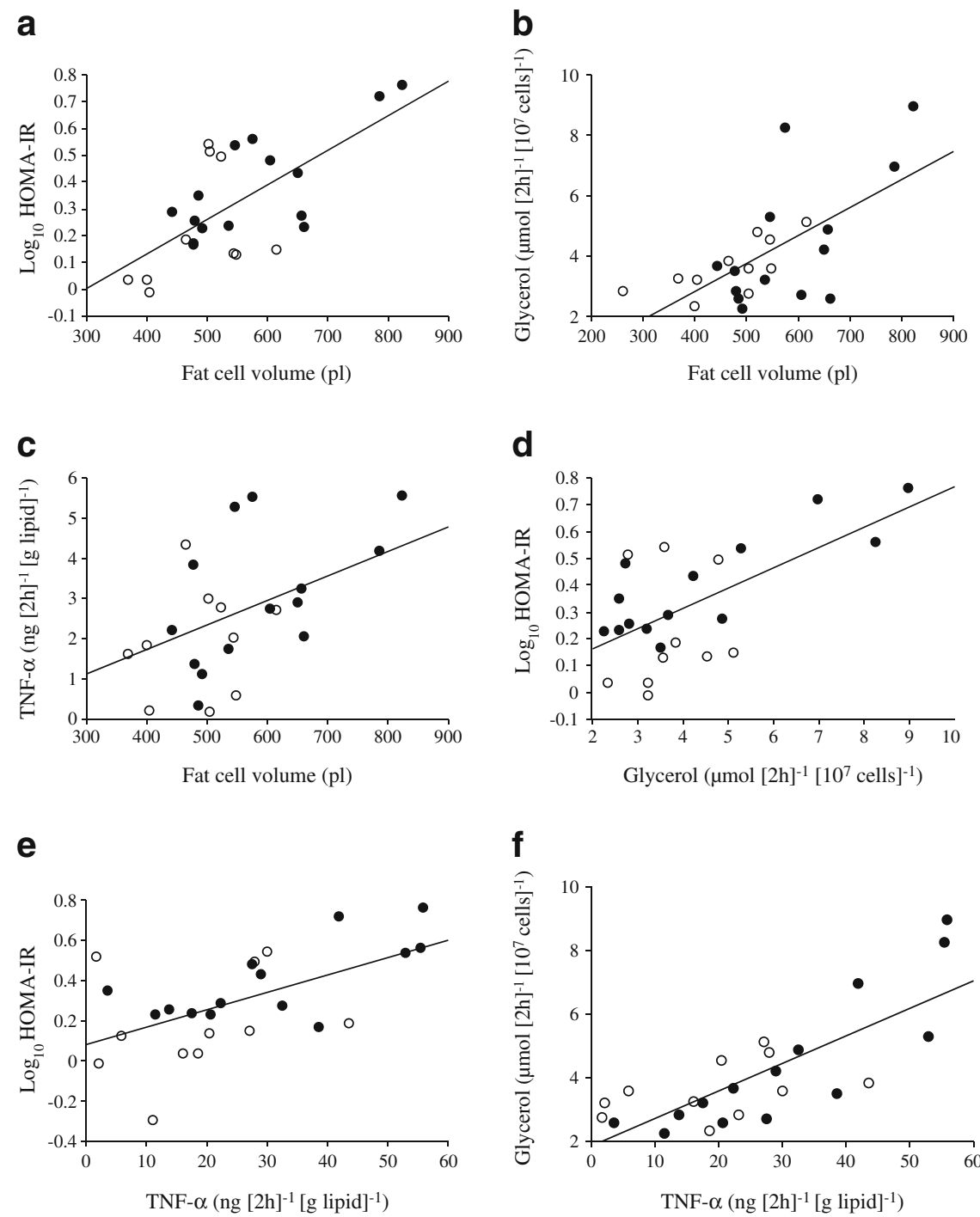

between the two groups. BMP4, DKK1 and WISP2, key genes involved in the regulation of adipogenesis, were selected for mRNA expression analysis since previous reports indicated that expression of these genes is altered with impaired adipogenesis [16]. BMP4 expression in the progenitor cell fraction $\left(\mathrm{CD} 45^{-} \mathrm{CD} 34^{+} \mathrm{CD} 31^{-}\right.$) correlated negatively and significantly with fat cell size in the entire group of individuals (Fig. 4a). $D K K 1$ expression showed a negative correlation trend $(r=$ $-0.366, p=0.086$; Fig. $4 \mathrm{~b}$ ) and WISP 2 a positive correlation trend $(r=0.383, p=0.065$; data not shown) with fat cell size. In addition, we quantified the expression of four genes involved in the later stages of adipogenesis, the expressions of which have been shown to have an impact on WAT morphology$E B F 1, P P A R \gamma, C E B P \alpha$ and SLC2A4 (GLUT4). Due to the strong upregulation of these genes during adipogenesis, we chose to investigate their expression in adipose tissue, which contains mature adipocytes. In scWAT, adipocyte size correlated significantly and negatively with expression of all four genes (Fig. 5a-d).

\section{Discussion}

To the best of our knowledge, data on adipose inflammation, fat cell size and lipolysis have not been reported before in the non-obese type 2 diabetes state. Quite surprisingly we observed no differences in lipolysis and secretion of inflammatory proteins when non-obese type 2 diabetes patients were compared with age-, weight- and body fat mass-matched healthy individuals. However, fat cell size was markedly larger in diabetic patients, suggesting that scWAT is hypertrophic in non-obese type 2 diabetes. It is very likely that scWAT hypertrophy per se, rather than diabetes status, is important for the observed link between fat cell size and adipose or clinical variables. Thus, in the entire cohort, fat cell size correlated positively with lipolysis, insulin resistance and secretion of inflammatory proteins. TNF- $\alpha$ could be a driving force in these relationships since scWAT secretion of this cytokine correlated with lipolysis and insulin resistance. This notion is further supported by previous findings demonstrating a 
Fig. 2 FACS sorting protocol for WAT SVF. Gating for representative samples of healthy individuals (a) and patients with type 2 diabetes (b) are shown. Fractions of progenitor cells (CD45 $\left.{ }^{-} \mathrm{CD} 34^{+} \mathrm{CD} 31^{-}\right), \mathrm{CD}^{+}$ T lymphocytes (CD45 $\left.\mathrm{CD} 14^{-} \mathrm{CD} 3^{+} \mathrm{CD}^{+}\right)$and $\mathrm{M} 1$ $\left(\mathrm{CD} 45^{+} \mathrm{CD} 14^{+} \mathrm{CD} 206^{+} \mathrm{CD} 11 \mathrm{c}^{+}\right)$ and $\mathrm{M} 2\left(\mathrm{CD} 45^{+} \mathrm{CD} 14^{+}\right.$

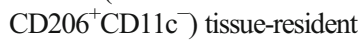
macrophages were collected and lysed for RNA expression analysis. $\mathrm{M} \Phi$, macrophages a
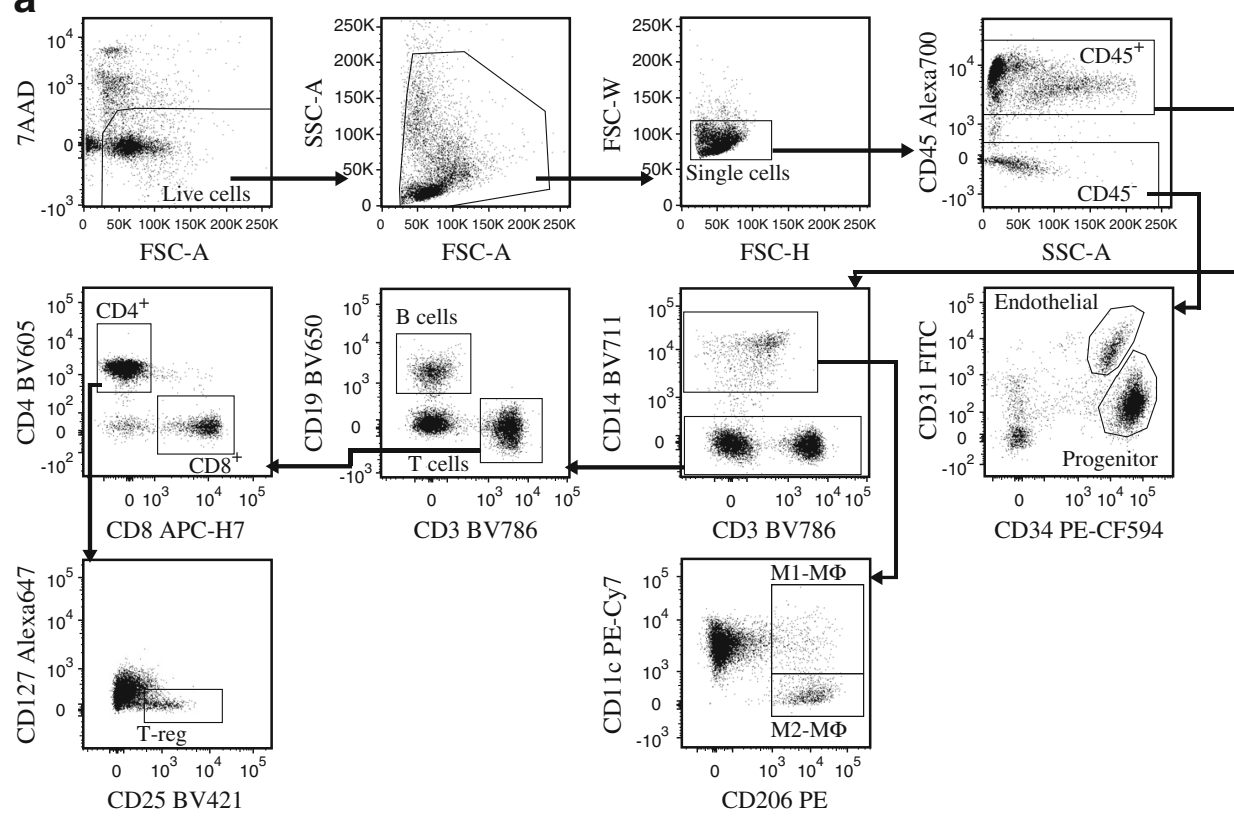

CD34 PE-CF59

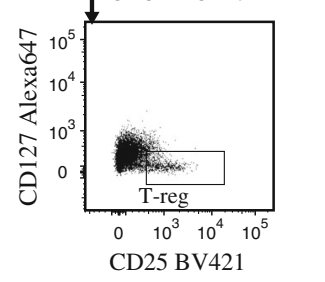

b
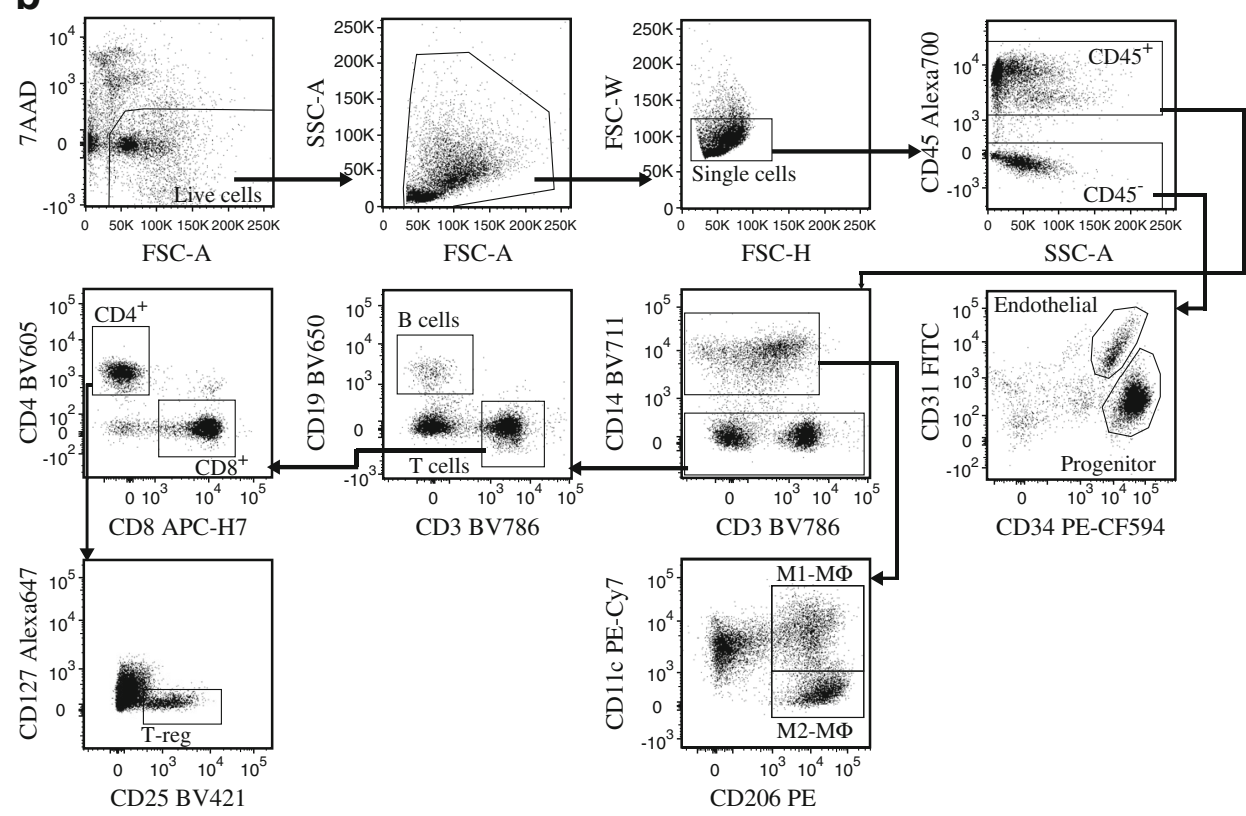

correlation between scWAT fat cell size and TNF- $\alpha$ secretion in healthy lean young women [9].

How could fat cell size play a role in type 2 diabetes? A phenotype characterised by smaller adipocytes, as well as increased adipocyte number in scWAT, correlates with increased insulin sensitivity [27] and a beneficial metabolic profile [28]. Furthermore, genetic predisposition for type 2 diabetes associates with adipocyte hypertrophy in non-obese first-degree relatives [29]. Finally, several studies show that enlarged fat cell size confers an increased risk of developing type 2 diabetes $[10,11,30]$. When these findings are put together it is

tempting to speculate that scWAT hypertrophy independent of excess body fat is an important defect, which triggers local inflammation and impaired lipolysis and these, in turn, facilitate the development of type 2 diabetes. Whether fat cell enlargement is an early defect in the development of diabetes remains to be demonstrated in long-term prospective studies of non-obese patients.

Our study on SVF corroborates previous findings that there were no significant differences in cell populations when comparing the scWAT of lean individuals and metabolically healthy obese individuals with that of metabolically unhealthy 
Table 2 Frequency of cell populations in subcutaneous SVF determined by flow cytometry

\begin{tabular}{|c|c|c|c|}
\hline Variable & Healthy controls & Type 2 diabetes patients & $p$ value \\
\hline$n$ & 12 & 14 & \\
\hline Total CD $45^{+}$ & $63.6 \pm 18.8$ & $69.3 \pm 17.5$ & 0.43 \\
\hline Progenitor cell fraction & $19.5 \pm 13.5$ & $18.8 \pm 15.7$ & 0.90 \\
\hline B cells & $5.7 \pm 3.0$ & $4.9 \pm 2.6$ & 0.48 \\
\hline $\mathrm{T}$ cells & $32.6 \pm 9.0$ & $36.9 \pm 12.4$ & 0.32 \\
\hline $\mathrm{CD} 4^{+} \mathrm{T}$ cells & $19.1 \pm 6.1$ & $21.3 \pm 9.1$ & 0.48 \\
\hline T-reg cells & $1.3 \pm 0.4$ & $1.4 \pm 0.8$ & 0.59 \\
\hline $\mathrm{CD}^{+} \mathrm{T}$ cells & $11.4 \pm 6.1$ & $13.6 \pm 8.3$ & 0.47 \\
\hline $\mathrm{CD} 4^{+} / \mathrm{CD}^{+}{ }^{+}$ratio & $2.1 \pm 1.1$ & $2.1 \pm 1.5$ & 0.98 \\
\hline $\mathrm{T}$ cell/B cell ratio & $6.5 \pm 2.2$ & $9.4 \pm 4.8$ & 0.07 \\
\hline Total ATM & $2.2 \pm 1.9$ & $3.8 \pm 4.0$ & 0.20 \\
\hline $\mathrm{M} 1-\mathrm{M} \Phi$ & $0.9 \pm 0.9$ & $2.0 \pm 2.2$ & 0.12 \\
\hline $\mathrm{M} 2-\mathrm{M} \Phi$ & $1.3 \pm 1.3$ & $1.8 \pm 1.9$ & 0.41 \\
\hline $\mathrm{M} 1 / \mathrm{M} 2$ ratio & $0.8 \pm 0.8$ & $1.2 \pm 0.7$ & 0.28 \\
\hline Endothelial cells & $0.8 \pm 0.6$ & $1.0 \pm 0.9$ & 0.70 \\
\hline
\end{tabular}

Data are mean $\pm \mathrm{SD}$

Cell frequencies are expressed as \% of live cells

$\mathrm{M} \Phi$, macrophages obese patients [31]. In the present cohort, cell populations in scWAT SVF of type 2 diabetes patients and healthy controls did not differ significantly. However, the M1/M2 macrophage ratio correlated with fat cell volume in the whole cohort. Furthermore, correlations between the M1/M2 macrophage ratio and TNF- $\alpha$ secretion as well as with glycerol release suggest that a switch of the macrophage phenotype towards M1 proinflammatory macrophages might contribute to the development of an unfavourable insulin-resistant metabolic phenotype in non-obese WAT in a similar way to that reported for obese WAT [3, 4, 32-34]. An increase in the T cell populations in WAT, as well as inflammatory $\mathrm{T}$ cell predominance in the circulation, has been associated with obesity [35-37]. In contrast to previous reports in obesity, the major $\mathrm{T}$ cell populations $\left(\mathrm{CD}^{+}\right.$and $\left.\mathrm{CD} 8^{+}\right)$did not associate with any of the adipose tissue phenotypes in our non-obese participants. Although T-reg cells and their subtypes are suggested to regulate inflammatory and metabolic phenotype of murine WAT, there are no previous reports on WAT-resident T-reg cells in human WAT. An inverse correlation between FOXP 3 (a T-reg specific marker) mRNA expression in visceral WAT vs scWAT and BMI in morbidly obese individuals has been reported [38]. We show that T-reg frequency is similar in the scWAT of non-obese type 2 diabetes patients and healthy controls.

Table 3 Effect of type 2 diabetes on fat cell size and SVF composition

\begin{tabular}{|c|c|c|c|c|}
\hline Variable & Short-term type 2 diabetes & $p$ value & Long-term type 2 diabetes & $p$ value \\
\hline$n$ & 7 & - & 5 & - \\
\hline Plasma glucose, mmol/1 & $7.3 \pm 1.4$ & $<0.001$ & $7.1 \pm 1.1$ & $<0.001$ \\
\hline Adipocyte volume, pl & $586.1 \pm 123.2$ & 0.03 & $597.8 \pm 145.2$ & 0.04 \\
\hline $\log _{10}$ HOMA-IR & $0.4 \pm 0.2$ & 0.27 & $0.3 \pm 0.2$ & 0.63 \\
\hline$M$ value, mmol glucose $(\mathrm{kg})^{-1}(\min )^{-1}$ & $0.019 \pm 0.014^{\mathrm{a}}$ & 0.62 & $0020 \pm \mathrm{NA}^{\mathrm{a}}$ & 0.31 \\
\hline 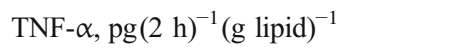 & $2,433.1 \pm 1,263.6$ & 0.38 & $2,874.2 \pm 1,815.8$ & 0.21 \\
\hline 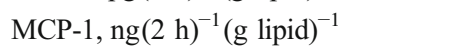 & $9.0 \pm 4.0$ & 0.60 & $5.6 \pm 3.2$ & 0.48 \\
\hline Total ATM & $5.6 \pm 4.7$ & 0.04 & $2.5 \pm 2.6$ & 0.77 \\
\hline $\mathrm{M} 1-\mathrm{M} \Phi$ & $2.9 \pm 2.6$ & 0.02 & $1.3 \pm 1.4$ & 0.42 \\
\hline
\end{tabular}

Data are mean \pm SD

Cell frequencies are expressed as \% of live cells

${ }^{\text {a }} M$ value measurements were available for five patients with short-term diabetes and one patient with long-term diabetes

$p$ values are calculated against healthy controls as displayed in Table 1 and Table 2

$\mathrm{M} \Phi$, macrophages 
Fig. 3 Inter-relationship between frequencies of WAT M1/M2 volume $(\rho=0.45, p=0.026)$ (a), TNF- $\alpha$ secretion $(\rho=0.47$, $p=0.019)(\mathbf{b})$ and glycerol release $(\rho=0.43, p=0.031)$ (c). (d) Relation between percentage of WAT M1 macrophages ( $\%$ of live cells) and TNF- $\alpha$ secretion $(\rho=0.44, p=0.027)$. Associations were analysed using Spearman's correlation test in an entire cohort of 26 individuals. White circles, individuals with type 2 diabetes macrophage ratio and fat cell healthy controls; black circles,
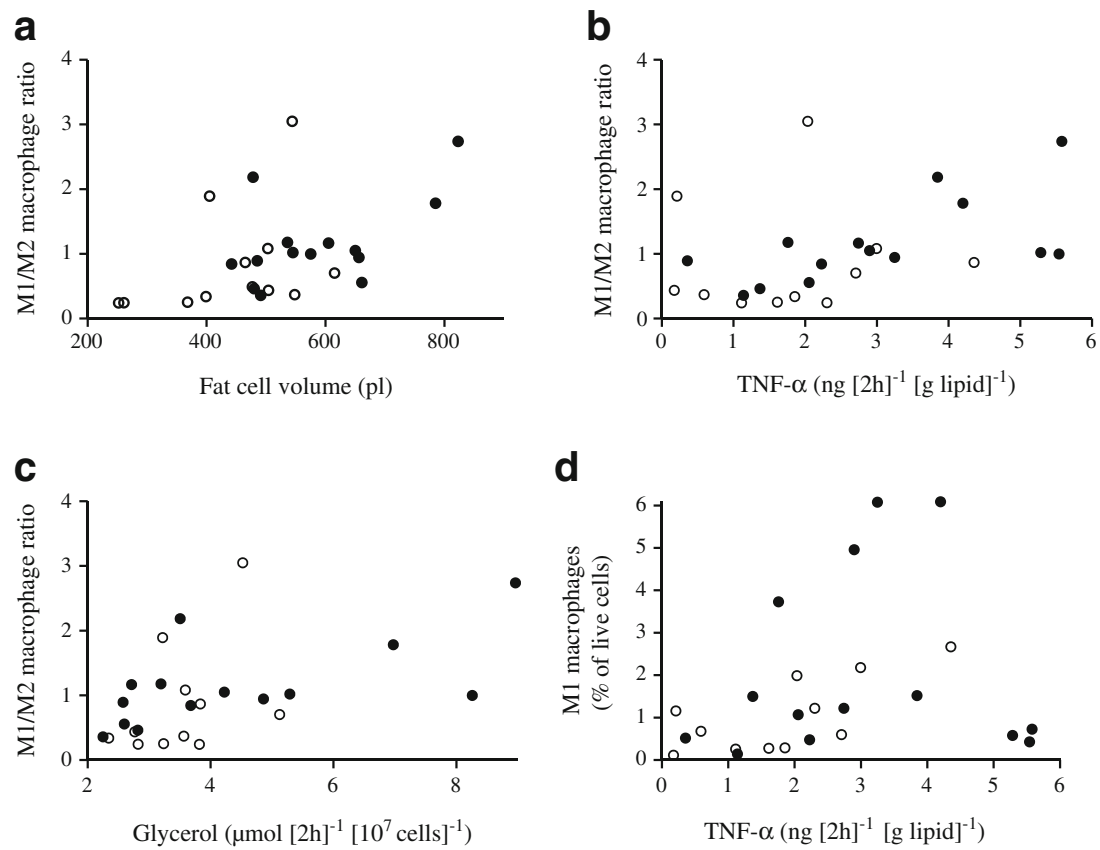

Furthermore, FOXP3 expression in the $\mathrm{CD} 4^{+} \mathrm{T}$ cell population, as well as in scWAT samples, did not differ between the groups. Although the T-reg population correlated positively with TNF- $\alpha$ and glycerol secretion, we could not confirm this finding by quantification of FOXP3 expression in the $\mathrm{CD} 4^{+}$ $\mathrm{T}$ cell fraction (data not shown). In a previous human study, T-reg cells were found to be increased in the peripheral blood of morbidly obese patients, although no correlation with insulin resistance was observed [39]. Clearly the role of this important cell population in type 2 diabetes needs further investigation.

Which molecular events cause scWAT hypertrophy in type 2 diabetes? Defective subcutaneous fat mass expandability has been proposed as a mechanism explaining ectopic fat accumulation and development of type 2 diabetes. In line with this, previous studies suggest that impaired adipogenesis linked to WNT-signalling and peroxisome proliferatoractivated receptor $\gamma(\operatorname{PPAR} \gamma)$ activation may play a role

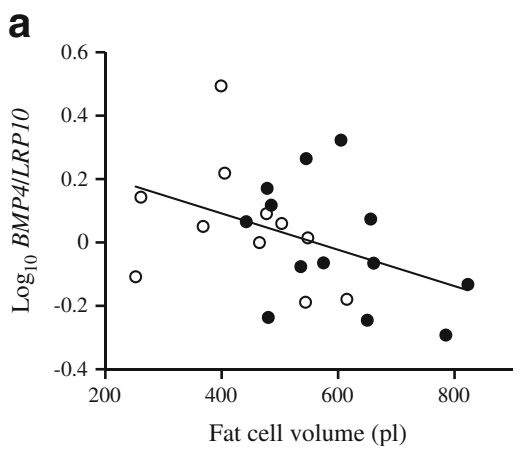

Fig. 4 Inter-relationship between $B M P 4$ expression in progenitor cell fraction and fat cell volume. Expression of BMP4 (a) and DKK1 (b) was analysed by RT-qPCR and association with fat cell size $(r=-0.41$,
[40, 41]. Bone morphogenetic protein 4 plays a critical part in early adipogenesis by dissociating WNT1-inducible signalling pathway protein 2 (a negative regulator of adipogenesis) and zinc finger protein 423 (ZNF423), thus allowing ZNF423 to relocate to the nucleus and start the adipogenesis programme $[16,40,41]$. In addition, early B cell factor 1 (EBF1) is a well-described regulator of adipogenesis [42], and we recently observed that reduced EBF1 levels and activity promote scWAT hypertrophy in part via interactions involving PPAR $\gamma$ [43]. We observed a trend towards higher expression of WISP 2 and lower expression of its inhibitor $D K K 1$ in progenitor cells of non-obese hypertrophic scWAT. Furthermore, the negative correlation of BMP4 expression in the progenitor cell fraction with fat cell size and the inverse relationship between adipocyte size and the expression of $E B F 1, C E B P \alpha$ and PPAR $\gamma$ in scWAT are indicative of a reduced differentiation capability of enlarged fat cells in our cohort. However, due to the small tissue sample sizes, we

b

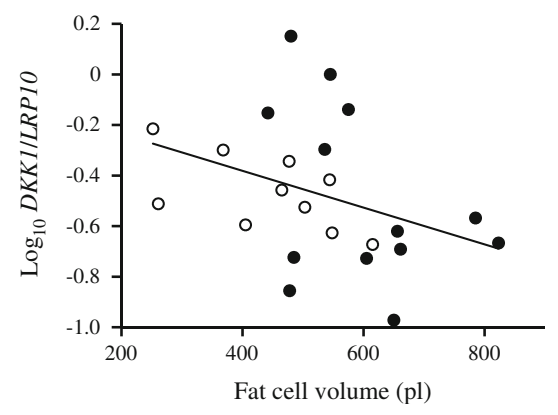

$p=0.045$ for $B M P 4 ; r=-0.366, p=0.086$ for $D K K 1$ ) was analysed using Pearson's correlation test in 24 patients. White circles, healthy controls; black circles, individuals with type 2 diabetes 
Fig. 5 Inter-relationship between the expression of PPAR $\gamma(\mathbf{a})$, $E B F 1$ (b), $C E B P \alpha$ (c) and $S L C 2 A 4$ (d) in scWAT and fat cell volume. Gene expression was analysed by RT-qPCR. The association of $P P A R \gamma(r=-0.47$, $p=0.014), E B F 1 \quad(r=-0.40$, $p=0.038), C E B P \alpha(r=-0.522$, $p=0.005)$, SLC $2 A 4$ ( $r=-0.643$, $p=0.0003$ ) with fat cell size was analysed using Pearson's correlation test in the entire cohort of 27 individuals. White circles, healthy controls; black circles, individuals with type 2 diabetes a

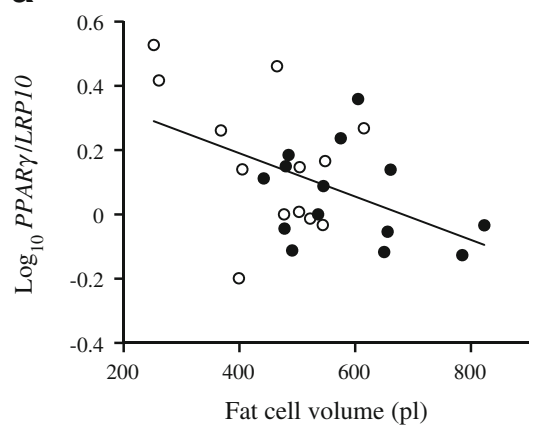

C

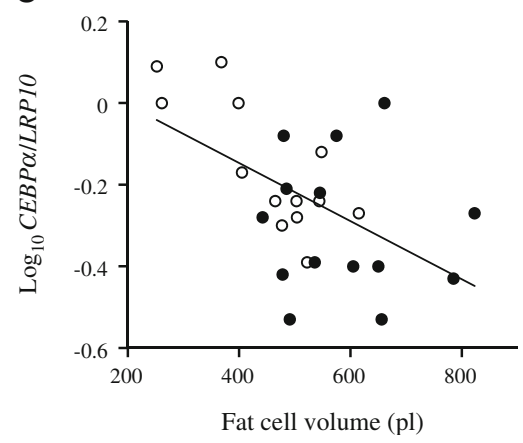

b

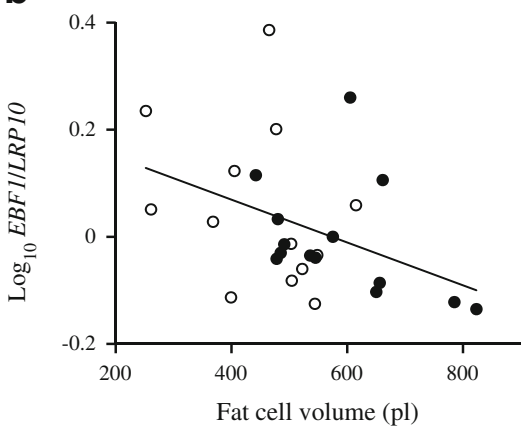

d

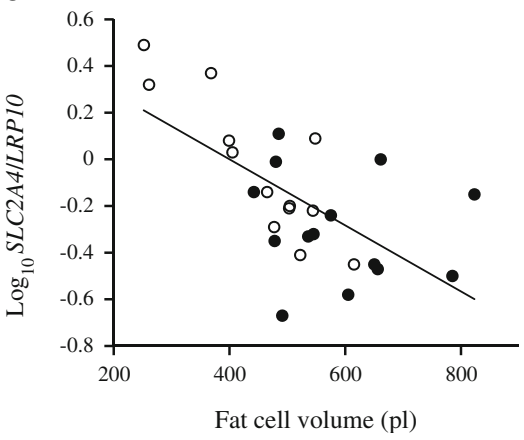

were not able to perform in vitro differentiation experiments to further support this hypothesis. In addition, a strong association between low expression of SLC $2 A 4$ and large cell size (Fig. 5d) was observed, as well as low $S L C 2 A 4$ expression and insulin resistance (HOMA-IR $[r=-0.58, p=0,002], M$ value $[r=0.697, p=0.002$ ] [data not shown]), which corroborate findings from an earlier study in non-obese individuals [44].

Although we have employed a highly complex protocol with 13 colour FACS sorting of adipose SVF to characterise WAT residing cell populations, the study has some methodological limitations, among which the amount of patient material and small cohort size are most important. Although the number of participants included in the study $(n=27)$ matches well a number reported in many other studies where in-depth characterisation of adipose tissue has been performed [44-46], the current dataset should be considered as a pilot report and further studies in larger independent cohorts need to be performed to further strengthen key results. Furthermore, samples obtained by needle biopsies were too small $(2.33 \pm 1.05 \mathrm{~g})$ and obtained yields of SVF cells $(243,500 \pm 142,325$ cells $)$ were not sufficient to enable analyses of immune cell activation or cytokine secretion as well as differentiation of sorted progenitor cells. Also, we could not examine the visceral adipose depot in these individuals for obvious ethical reasons. Therefore, the phenotype of visceral WAT cell populations in nonobese patients with type 2 diabetes needs to be established by future studies. In addition, the patients received different forms of oral glucose-lowering pharmacotherapy, including metformin. Metformin can inhibit human lipolysis both in vivo and in in vitro adipocyte cultures [47, 48]. However, the anti-lipolytic effect of metformin is observed only upon stimulated lipolysis, and should not affect the presently investigated spontaneous rate.

Our data support earlier findings that fat cell size may predispose the progression of type 2 diabetes. The observation that patients with short-term, but not those with long-term, diabetes duration had elevated numbers of M1 as well as total ATMs suggests that adipose tissue is inflamed already at early stages of non-obese type 2 diabetes, but that compensatory or adaptive mechanisms might counteract adipose tissue inflammation during disease progression. Alternatively, our patient group who had long-term diabetes and who did not require insulin treatment might represent a group of individuals with a milder form of disease and non-inflamed adipose tissue. Admittedly, the number of individuals in each group was very small and this limits the possibility of drawing firm conclusions. It would nevertheless be interesting to follow up progression of diabetes in patients with small and large proportions of M1 ATMs and determine whether less-inflamed adipose tissue at early time points of the disease is connected with better prognosis.

Taken together, the results of our study indicate that nonobese patients with type 2 diabetes have larger subcutaneous adipocytes compared with healthy control individuals and that this could be due to the attenuated differentiation capacity of adipocyte progenitor cells. Adipose hypertrophy rather than 
type 2 diabetes per se is associated with alterations in lipolysis, scWAT inflammation and impaired insulin sensitivity in scWAT.

\begin{abstract}
Acknowledgements The technical assistance of G. Åström, E. Sjölin, E. Dungner, K. Wåhlén, Y. Widlund and K. Hertel (Dept of Medicine Huddinge, Karolinska Institutet, Sweden) is greatly appreciated.
\end{abstract}

Funding This work was supported by the Swedish Research Council, the Novo Nordisk Foundation, the Diabetes Research Program at Karolinska Institutet and the Knut and Alice Wallenberg Foundation.

Duality of interest The authors declare that there is no duality of interest associated with this manuscript.

Contribution statement JRA, JL and PA designed the study and all coauthors researched and analysed data. DPA, JB and MR selected and characterised the clinical cohort and ID and JL designed flow cytometry protocols. JRA and JL wrote the manuscript. All co-authors contributed to the discussion, revised the manuscript critically and approved a final version. $\mathrm{JL}$ is the guarantor of this work and takes full responsibility for the full content.

\section{References}

1. DeFuria J, Belkina AC, Jagannathan-Bogdan M et al (2013) B cells promote inflammation in obesity and type 2 diabetes through regulation of $\mathrm{T}$ cell function and an inflammatory cytokine profile. Proc Natl Acad Sci U S A 110:5133-5138

2. Stefanovic-Racic M, Yang X, Turner MS et al (2012) Dendritic cells promote macrophage infiltration and comprise a substantial proportion of obesity-associated increases in $\mathrm{CD} 11 \mathrm{c}+$ cells in adipose tissue and liver. Diabetes 61:2330-2339

3. Weisberg SP, McCann D, Desai M et al (2003) Obesity is associated with macrophage accumulation in adipose tissue. J Clin Invest 112:1796-1808

4. Wentworth JM, Naselli G, Brown WA et al (2010) Proinflammatory CD11c+CD206+ adipose tissue macrophages are associated with insulin resistance in human obesity. Diabetes 59:1648-1656

5. Lee BC, Lee J (2014) Cellular and molecular players in adipose tissue inflammation in the development of obesity-induced insulin resistance. Biochim Biophys Acta 1842:446-462

6. O'Rourke RW, White AE, Metcalf MD et al (2011) Hypoxiainduced inflammatory cytokine secretion in human adipose tissue stromovascular cells. Diabetologia 54:1480-1490

7. Ouchi N, Parker JL, Lugus JJ, Walsh K (2011) Adipokines in inflammation and metabolic disease. Nat Rev Immunol 11:85-97

8. Glass CK, Olefsky JM (2012) Inflammation and lipid signaling in the etiology of insulin resistance. Cell Metab 15:635-645

9. Arner E, Ryden M, Arner P (2010) Tumor necrosis factor alpha and regulation of adipose tissue. N Engl J Med 362:1151-1153

10. Weyer C, Foley JE, Bogardus C et al (2000) Enlarged subcutaneous abdominal adipocyte size, but not obesity itself, predicts type II diabetes independent of insulin resistance. Diabetologia 43:1498-1506

11. Lonn M, Mehlig K, Bengtsson C, Lissner L (2010) Adipocyte size predicts incidence of type 2 diabetes in women. FASEB J 24:326-331
12. Arner P, Arner E, Hammarstedt A, Smith U (2011) Genetic predisposition for type 2 diabetes, but not for overweight/obesity, is associated with a restricted adipogenesis. PLoS One 6, e18284

13. Rosengren AH, Braun M, Mahdi T et al (2012) Reduced insulin exocytosis in human pancreatic beta-cells with gene variants linked to type 2 diabetes. Diabetes 61:1726-1733

14. Barroso I, Gurnell M, Crowley VE et al (1999) Dominant negative mutations in human PPAR $\gamma$ associated with severe insulin resistance, diabetes mellitus and hypertension. Nature 402:880-883

15. Kozusko K, Tsang VH, Bottomley W et al (2015) Clinical and molecular characterization of a novel PLIN1 frameshift mutation identified in patients with familial partial lipodystrophy. Diabetes 64:299-310

16. Gustafson B, Hammarstedt A, Hedjazifar S, Smith U (2013) Restricted adipogenesis in hypertrophic obesity: the role of WISP2, WNT, and BMP4. Diabetes 62:2997-3004

17. Matthews DR, Hosker JP, Rudenski AS et al (1985) Homeostasis model assessment: insulin resistance and beta-cell function from fasting plasma glucose and insulin concentrations in man. Diabetologia 28:412-419

18. Kolaczynski JW, Morales LM, Moore JH Jr et al (1994) A new technique for biopsy of human abdominal fat under local anaesthesia with lidocaine. Int J Obes Relat Metab Disord 18:161-166

19. Hoffstedt J, Arner E, Wahrenberg H et al (2010) Regional impact of adipose tissue morphology on the metabolic profile in morbid obesity. Diabetologia 53:2496-2503

20. Rodbell M (1964) Metabolism of isolated fat cells. I. Effects of hormones on glucose metabolism and lipolysis. J Biol Chem 239:375-380

21. Eriksson-Hogling D, Andersson DP, Backdahl J et al (2015) Adipose tissue morphology predicts improved insulin sensitivity following moderate or pronounced weight loss. Int J Obes (Lond) 39:893-898

22. Hirsch J, Gallian E (1968) Methods for the determination of adipose cell size in man and animals. J Lipid Res 12:91-95

23. van Harmelen V, Skurk T, Hauner H (2005) Primary culture and differentiation of human adipocyte precursor cells. Methods Mol Med 107:125-135

24. Arner E, Westermark PO, Spalding KL (2010) Adipocyte turnover: relevance to human adipose tissue morphology. Diabetes 59:105-109

25. Zeyda M, Farmer D, Todoric J et al (2007) Human adipose tissue macrophages are of an anti-inflammatory phenotype but capable of excessive pro-inflammatory mediator production. Int J Obes (Lond) 31:1420-1428

26. Liu W, Putnam AL, Xu-Yu Z et al (2006) CD127 expression inversely correlates with FoxP3 and suppressive function of human CD4+ T reg cells. J Exp Med 203:1701-1711

27. Andersson DP, Eriksson Hogling D, Thorell A et al (2014) Changes in subcutaneous fat cell volume and insulin sensitivity after weight loss. Diabetes Care 37:1831-1836

28. Ryden M, Andersson DP, Bergstrom IB, Arner P (2014) Adipose tissue and metabolic alterations: regional differences in fat cell size and number matter, but differently: a cross-sectional study. J Clin Endocrinol Metab 99:E1870-E1876

29. Henninger AM, Eliasson B, Jenndahl LE, Hammarstedt A (2014) Adipocyte hypertrophy, inflammation and fibrosis characterize subcutaneous adipose tissue of healthy, non-obese subjects predisposed to type 2 diabetes. PLoS One 9, e105262

30. Cotillard A, Poitou C, Torcivia A et al (2014) Adipocyte size threshold matters: link with risk of type 2 diabetes and improved insulin resistance after gastric bypass. J Clin Endocrinol Metab 99:E1466-E1470

31. Esser N, L'Homme L, de Roover A et al (2013) Obesity phenotype is related to NLRP3 inflammasome activity and immunological profile of visceral adipose tissue. Diabetologia 56:2487-2497 
32. Fujisaka S, Usui I, Bukhari A et al (2009) Regulatory mechanisms for adipose tissue M1 and M2 macrophages in diet-induced obese mice. Diabetes 58:2574-2582

33. Hotamisligil GS, Shargill NS, Spiegelman BM (1993) Adipose expression of tumor necrosis factor-alpha: direct role in obesitylinked insulin resistance. Science 259:87-91

34. Xu H, Barnes GT, Yang Q et al (2003) Chronic inflammation in fat plays a crucial role in the development of obesity-related insulin resistance. J Clin Invest 112:1821-1830

35. Travers RL, Motta AC, Betts JA et al (2014) The impact of adiposity on adipose tissue-resident lymphocyte activation in humans. Int J Obes (Lond) 39:762-769

36. van Beek L, Lips MA, Visser A et al (2014) Increased systemic and adipose tissue inflammation differentiates obese women with T2DM from obese women with normal glucose tolerance. Metabolism 63:492-501

37. Viardot A, Heilbronn LK, Samocha-Bonet D et al (2012) Obesity is associated with activated and insulin resistant immune cells. Diabetes Metab Res Rev 28:447-454

38. Feuerer M, Herrero L, Cipolletta D et al (2009) Lean, but not obese, fat is enriched for a unique population of regulatory $\mathrm{T}$ cells that affect metabolic parameters. Nat Med 15:930-939

39. van der Weerd K, Dik WA, Schrijver B et al (2012) Morbidly obese human subjects have increased peripheral blood CD4+ T cells with skewing toward a Treg- and Th2-dominated phenotype. Diabetes 61:401-408

40. Hammarstedt A, Hedjazifar S, Jenndahl L et al (2013) WISP2 regulates preadipocyte commitment and PPAR $\gamma$ activation by BMP4. Proc Natl Acad Sci U S A 110:2563-2568
41. Gustafson B, Smith U (2012) The WNT inhibitor Dickkopf 1 and bone morphogenetic protein 4 rescue adipogenesis in hypertrophic obesity in humans. Diabetes 61:1217-1224

42. Hesslein DG, Fretz JA, Xi Y et al (2009) Ebfl-dependent control of the osteoblast and adipocyte lineages. Bone 44:537-546

43. Gao H, Mejhert N, Fretz JA et al (2014) Early B cell factor 1 regulates adipocyte morphology and lipolysis in white adipose tissue. Cell Metab 19:981-992

44. Hammarstedt A, Graham TE, Kahn BB (2012) Adipose tissue dysregulation and reduced insulin sensitivity in non-obese individuals with enlarged abdominal adipose cells. Diabetol Metab Syndr 4:42

45. Jernas M, Palming J, Sjoholm K et al (2006) Separation of human adipocytes by size: hypertrophic fat cells display distinct gene expression. FASEB J 20:1540-1542

46. Gogebakan O, Osterhoff MA, Schuler R et al (2015) GIP increases adipose tissue expression and blood levels of MCP-1 in humans and links high energy diets to inflammation: a randomised trial. Diabetologia 58:1759-1768

47. Grisouard J, Timper K, Bouillet E et al (2011) Metformin counters both lipolytic/inflammatory agents-decreased hormone sensitive lipase phosphorylation at Ser-554 and -induced lipolysis in human adipocytes. Arch Physiol Biochem 117:209-214

48. Flechtner-Mors M, Ditschuneit HH, Jenkinson CP et al (1999) Metformin inhibits catecholamine-stimulated lipolysis in obese, hyperinsulinemic, hypertensive subjects in subcutaneous adipose tissue: an in situ microdialysis study. Diabet Med 16:1000-1006 